Hispania Sacra, LX

122, julio-diciembre 2008, 635-658, ISSN: 0018-215-X

\title{
LAS «MISIONES INTERIORES» EN LA CAMPAÑA DE BUENOS AIRES ENTRE DOS SIGLOS: DE LOS BORBONES A ROSAS
}

\author{
POR \\ MARÍA ElENA BARRAL \\ (Conicet-Unlu) \\ ROBERTO Di STEFANO \\ (Conicet-Uba)
}

\section{RESUMEN}

Las «misiones interiores» fueron promovidas por las autoridades políticas, requeridas por obispos y párrocos y llevadas a cabo por jesuitas, mercedarios y franciscanos. Tanto en Europa como en América, durante los siglos XVII, XVIII y XIX se plantearon como estrategias misionales para llevar la predicación y los sacramentos a regiones donde la presencia eclesiástica era débil. A menudo se proponían pacificar las comunidades más alejadas y conflictivas. La misión constituía un momento extraordinario de contacto con la religión y era planificada con un marcado carácter pedagógico, por lo que las tareas de los misioneros significaron una ayuda importante para los párrocos. Las «misiones interiores» involucraron a una amplia gama de actores: feligreses y eclesiásticos, autoridades civiles y religiosas, clero secular y regular. Este artículo se propone comparar este tipo de misiones en la campiña bonaerense en dos momentos de reformulación de las relaciones entre clero regular y clero secular por un lado y entre Iglesia y poder civil por otro durante el período colonial y el segundo gobierno de Juan Manuel de Rosas. Nos interesa plantear de qué modo y con qué motivaciones los poderes políticos apelaron a estas misiones, así como las características que las mismas asumieron en esos dos contextos históricos diversos, en los cuales se estaba transformando el lugar de las instituciones eclesiásticas en la sociedad y sus vínculos con los poderes gubernamentales.

PAlABRAS ClAVE: Misiones interiores, Campiña bonaerense, Reformas borbónicas, Juan Manuel de Rosas. 


\title{
THE «INTERIOR MISSIONS» IN THE COUNTRY OF BUENOS AIRES BETWEEN TWO CENTURIES: FROM BORBONES TO ROSAS
}

\begin{abstract}
The «misiones interiores» were promoted by the political authorities, required by bishops and parsons and carried out by Jesuits, Mercedarios and Franciscans. Both in Europe and America, during the seventeenth, eighteenth and nineteenth centuries they were conceived as missionary strategies to spread the teachings and the sacraments to areas of weak ecclesiastical presence, and they often sought to pacify the most distant and conflictive communities. The missions were an extraordinary moment of contact with religion, and were planned with a strong pedagogical character, so that the duties of the missionaries meant an important help to the parsons. The «misiones interiores» involved a wide range of actors: parishioners and churchmen, political and religious authorities, regular and secular clergy. This article offers a comparison between the missions developed in the countryside of Buenos Aires in two moments of change in the relationships between regular and secular clergy on one hand, and between the Church and the civil authorities on the other, during the colonial period and Juan Manuel de Rosas' second period of government. We want to highlight the way in which the civil powers resorted to these missions, and their characteristics in those two different historical contexts, in which the role of the ecclesiastical institutions in the social order and their ties with the civil powers were subject to modifications.
\end{abstract}

KEY WORDS: Missions, Countryside of Buenos Aires, Borbonic reforms, Juan Manuel de Rosas.

Recibido/Received 08-01-2008

Aceptado/Accepted 28-02-2008

Las misiones interiores fueron promovidas por las autoridades políticas, requeridas por obispos y párrocos y llevadas a cabo por jesuitas, mercedarios y franciscanos. Tanto en Europa como en América, durante los siglos XVII, XVIII y XIX se desarrollaron como estrategias misionales para llevar la predicación y los sacramentos a regiones donde la presencia eclesiástica era débil. A menudo se proponían además pacificar las comunidades más alejadas y conflictivas. Se trata además experiencias que involucraron a una amplia gama de actores: feligreses y eclesiásticos, autoridades civiles y religiosas, clero secular y regular. Este artículo se propone comparar las misiones que se llevaron a cabo en la campiña bonaerense durante el período virreinal y las que organizó el gobierno federal de Juan Manuel de Rosas en la década de 1830. Interesa observar de qué modo y con qué motivaciones los poderes políticos apelaron a estas misiones, así como las características que las mismas asumieron en dos contextos históricos diversos, el de las reformas borbónicas y el del segundo gobierno de Rosas. Ambos tienen en común el hecho de que en ambos casos se estaba trans-

Hispania Sacra, LX

122, julio-diciembre 2008, 635-658, ISSN: 0018-215-X 
formando el lugar de las instituciones eclesiásticas en la sociedad y sus vínculos con los poderes civiles.

\section{EL CONTEXTO}

Veamos cuáles eran las características de las áreas rurales recorridas por los misioneros. La campiña bonaerense, a pesar de no conformar una jurisdicción separada en la organización institucional colonial, poseía un perfil claramente reconocible y una entidad precisa en la percepción de los sujetos ${ }^{1}$. Desde el punto de vista de la administración civil formó parte de la jurisdicción de los cabildos de Buenos Aires y de Luján hasta 1822. Desde el punto de vista eclesiástico era parte del obispado de Buenos Aires, que tenía su sede en la ciudad capital $^{2}$. Se trata de un ámbito regional que, hasta la década de 1820, poseyó una población urbana cuantitativamente superior a la rural. La ciudad de Buenos Aires en vertiginoso crecimiento, cuadruplicó su población entre 1744 y 1810, y empujó el poblamiento aún más acelerado de su área rural, en gran parte a causa de la recepción de migrantes internos.

A tiempo que se estructuró en torno a una ciudad-puerto que vivió un acelerado proceso de crecimiento en la segunda mitad del siglo XVIII y adquirió la categoría de capital virreinal, esta región siguió constituyendo una sociedad de frontera en la que el límite con las sociedades indígenas no conquistadas se encontraba a apenas $200 \mathrm{~km}$. de la capital y un espacio regional en el que coexistían zonas de antigua colonización con zonas de ocupación muy reciente y hasta incierta en la frontera. Allí se configuraron poblados donde residían estancieros, labradores y pastores, hombres y mujeres y familias campesinas. Se trataba de comunidades que se iban formando al ritmo de la ocupación territorial, que afirmaron un tipo de producción y de ocupación de la tierra y dieron vida a intercambios comerciales centrados en «pulperías» y

${ }^{1}$ Sobre los estudios acerca de la campiña bonaerense pueden verse los siguientes balances: Juan Carlos Garavaglia y Jorge Gelman, «Rural History of the Río de la Plata, 1600-1850: Results of a Historiographical Renaissance», en Latin American Research Review, (30-3) 1995, pp. 75-105; Raúl FRADKIN y Jorge GELMAN, «Recorridos y desafíos de una historiografía. Escalas de observación y fuentes en la historia rural rioplatense», en Beatriz BRAGONI (ed.), Microanálisis. Ensayos de historiografía argentina, Buenos Aires, PrometeoLibros, 2004, pp. 31-54 y Jorge Gelman y Juan Carlos GaraVAGLIA, «Mucha tierra y poca gente: un nuevo balance historiográfico de la historia rural platense (17501850)», en Historia agraria: Revista de agricultura e historia rural, 15 (1998), pp. 29-50. Además puede verse Juan Carlos Garavaglia, Pastores y labradores de Buenos Aires, Buenos Aires, Ediciones de la Flor-IEHS-UPO, 1999.

2 Roberto Di Stefano y Loris Zanatta, Historia de la Iglesia Argentina, Buenos Aires, GrijalboMondadori, 2000; Roberto Di STEFANO, El púlpito y la plaza, Buenos Aires, Siglo veintiuno editores Argentina, 2004 y María Elena BARRAL, De sotanas por la pampa. Religión y sociedad en Buenos Aires rural tardocolonial, Buenos Aires, PrometeoLibros, 2007. 
tiendas. En la región se configuró de ese modo una serie de ecosistemas social-agrarios diversos en los que convivían la agricultura y la ganadería en distintos tipo de establecimientos y con diferentes modos de acceso a la tierra y en los cuales adquirió características diferenciadas el proceso de estructuración social.

Las estructuras parroquiales rurales, iniciadas en 1730, sufrieron modificaciones importantes a lo largo del siglo XVIII y las primeras décadas del XIX. La red parroquial empezó a consolidarse en las zonas de más temprana colonización hacia las últimas décadas del siglo XVIII y hacia la década de 1820 había alcanzado un significativo equilibrio entre los diversos partidos en que se distribuía políticamente el espacio.

Pero la situación se modificó sustancialmente en el siglo XIX como consecuencia de al menos dos procesos concurrentes: la preponderancia que asumió la presencia de las estructuras de poder institucional civil y militar y sus agentes ${ }^{3}$, es decir, la construcción del estado provincial, y la declinación de la importancia de las instituciones eclesiásticas y la reformulación que, acerca de su papel en el orden social, haría el naciente estado provincial a partir de la década de $1820^{4}$. Si, como pensamos, a lo largo del siglo XVIII las estructuras eclesiásticas tuvieron un papel fundante en los procesos de estructuración social y del poder institucional, hacia finales del período la imagen es completamente opuesta. La Iglesia era otra. El Estado, también.

Esos cambios se relacionan estrechamente con las alternativas políticas que sacudieron la vida de la región desde los Borbones a Rosas. La crisis de la monarquía alcanzó un punto sin retorno con la derrota de Trafalgar de 1805 y con las invasiones inglesas de 1806 y 1807, que pusieron en marcha un proceso de politización y militarización que devino revolucionario cuando se recibieron las noticias de la caída de la Junta Central en 1810.

En los años siguientes la guerra fue un dato casi permanente, a causa de la superposición de la guerra revolucionaria y la guerra civil entre Buenos Aires y el movimiento confederacionista liderado por José Gervasio de Artigas. En 1820 , derrotado por los caudillos disidentes, el Directorio se disolvió y las provincias que habían integrado el virreinato se constituyeron en estados sobera-

\footnotetext{
${ }^{3}$ Puede verse María Elena BARRAL y Raúl FrADKIN, «Los pueblos y la construcción de las estructuras de poder institucional en la campiña bonaerense (1785-1836)» en Boletín del Instituto de Historia Argentina y Americana Dr. Emilio Ravignani, 27, (2005) pp. 7-48; Jorge Gelman, «Justice, Etat et Societé. Le retablissement de l'ordre a Buenos Aires aprés l'independance», en Etudes Rurales, 149/150 (1999) pp. 111-124; Juan Carlos GARAVAGLIA, «La apoteósis de Leviathán: el estado de Buenos Aires durante la primera mitad del siglo XIX», en Latin American Research Review, 38 (2003), pp. 135-168 y Construir el estado, inventar la nación, Buenos Aires, PrometeoLibros, 2007 y Raúl FRADKIN (comp.), El poder y la vara. Buenos Aires, PrometeoLibros, 2007.

${ }^{4}$ Roberto di Stefano, El púlpito y la plaza..., cit.
}

Hispania Sacra, LX

122, julio-diciembre 2008, 635-658, ISSN: 0018-215-X 
nos. En tanto, la guerra había conducido a la ruina económica a parte de las elites provinciales y había desestructurado los espacios económico, político y eclesiástico.

Entre 1824 y 1827 se intentó restablecer la unidad de las provincias convocando a un congreso constituyente, pero las discusiones se complicaron por la guerra con el Brasil (1825-1828) y con la emergencia de una disputa entre centralistas -unitarios- y confederacionistas-federales. En el congreso prevalecieron las posturas de los unitarios, una de cuyas más conspicuas figuras, Bernardino Rivadavia fue elegido presidente de la república. La constitución promulgada por el congreso en 1826 encendió la guerra civil entre federales y unitarios y la unidad alcanzada se volvió a perder. En la Provincia de Buenos Aires, tras el fracaso de una revolución unitaria, asumió el gobierno de la provincia en diciembre de 1829 Juan Manuel de Rosas. Un Pacto Federal firmado de 1831 y sucesivamente ampliado dio forma a una confederación de provincias cuyo manejo de las relaciones exteriores fue cedido al gobernador de Buenos Aires. A partir de 1835, Rosas impuso un férreo control político sobre la provincia y se convirtió en el hombre fuerte del país, con capacidad de influir de manera decisiva en casi todas las demás.

Por lo que hace a la Iglesia, el clero secular había sido llamado a colmar el vacío que los jesuitas, tras su expulsión, dejaron en la pastoral y en la educación. La política eclesiástica borbónica buscó reducir la autonomía de las órdenes religiosas sujetándolas a la autoridad de los ordinarios diocesanos, frenar el proceso de amortización de propiedades inmuebles y quitar de raíz las «doctrinas laxas» que según la monarquía habían propagado los expulsos. El clero secular, hasta entonces débil, se convirtió en un par de decenios en columna vertebral de la Iglesia porteña.

Pero la revolución des-estructuró la geografía eclesiástica: la diócesis quedó muy pronto dividida en provincias enfrentadas, los diezmos no pudieron ser cobrados sino muy irregularmente, mientras las ordenaciones sacerdotales se desmoronaban y buena parte del clero era expulsado de la diócesis por razones políticas. En 1820 la caída del poder central agregó a esos problemas uno nuevo, porque cada una de las provincias reclamó el derecho de ejercer el patronato que habían detentado los Borbones y la revolución había juzgado legítimo heredar.

En Buenos Aires, la reforma eclesiástica de 1822 centralizó y estatizó las instituciones eclesiásticas poniéndolas bajo la obediencia del ordinario, suprimió casi todas las órdenes religiosas masculinas y reorientó la pastoral hacia las nuevas necesidades de la provincia convertida en estado soberano. El ascenso al poder de Rosas conllevó algunos cambios en ese esquema, que, sin embargo, permaneció sustancialmente inalterado: en 1835 se admitió el regreso de los dominicos a su antiguo convento y en 1836 retornaron los jesuitas, que pronto 
serían nuevamente expulsados por desavenencias con el Restaurador de las Leyes 5 .

\section{LAS MISIONES «COLONIALES»}

El inicio de las misiones interiores en América ha sido ubicado a fines del siglo XVII cuando el renacimiento del impulso misionero llevó a los franciscanos a transformar el Convento de Querétaro de Nueva España en el primer Colegio Apostólico de Propaganda Fide de la América española ${ }^{6}$. Según Brading, estos colegios se proponían tanto convertir a los indios infieles que vivían en las fronteras del imperio como predicar a los fieles católicos de las provincias centrales de México y Perú7. Estas misiones, con antecedentes en Europa desde el siglo XVII, han sido consideradas una de las manifestaciones más importantes de la ofensiva pastoral pos-tridentina e interpretadas como intervenciones pastorales extraordinarias, de marcado carácter pedagógico, orientadas a reorganizar la vida de las comunidades y a operar en el ámbito de las conciencias por medio de la predicación y de la confesión ${ }^{8}$.

Distintas órdenes religiosas organizaron estas misiones en la campiña bonaerense a lo largo del siglo XVIII. Las primeras fueron obra de los jesuitas, por lo que sería precisamente este antecedente el que el Cabildo de Buenos Aires recordaría en 1788 cuando los regidores propusieron la reinstalación de las antiguas misiones para controla y educar a los habitantes de la campiña. Planteaban en aquella oportunidad:

5 Roberto Di Stefano, «El laberinto religioso de Juan Manuel de Rosas», Anuario de Estudios Americanos 63-1 (2006), pp. 19-50.

6 Otros Colegios de Misioneros se fundaron en Ciudad de México (1731), Ocopa (1734), Chillán (1754), Tarija (1755), Moquegua y Tarata (1795), véase Joseph BARNADAS, «La Iglesia católica en la Hispanoamérica colonial», en Leslie BetTHEL (ed), Historia de América Latina, vol. 2, Barcelona, Crítica, 1990, pp. 185-207.

7 David Brading, «La devoción católica y la heterodoxia en el México Borbónico», en Clara GARCía Ayluardo y Manuel Ramos Medina (coords.), Manifestaciones religiosas en el mundo colonial americano, México, INAH-UIA-CONDUMEX, 1997, pp. 25-49.

8 Entre los mejores estudios sobre las misiones interiores, rurales o populares en Europa pueden verse: Francisco Rico CALlado, Las misiones interiores en la España de los siglos XVII-XVIII, Tesis Doctoral Universidad de Alicante, 2001; Federico PALOMO DEL BARRIO, Fazer dos campos escolas excelentes: los jesuitas de Evora, la misión interior y el disciplinamiento social en la época confesional (1551-1630), Tesis Doctoral, IUE, Florencia, 2000; Louis CHÂTELLIER, L, La religion des pauvres. Les missions rurales en Europe et la formation du catholicisme moderne XVIe-XIXe, París, Ed. Aubier, 1993; F. GIORgINI, La predicazione e le missioni popolari tra il 1815 e il 1870, in AAVV, Problemi di storia della Chiesa. Dalla Restaurazione all'unità d'Italia, Napoli, 1985, pp. 79-106; G. ORLANDI, «La missione popolare in età moderna», in Storia dell'Italia religiosa, 2. L'età moderna, a cura di G. De Rosa e T. Gregory, Roma-Bari, 1994. pp. 419-452; A. ProsPerI «El misionero», en R. VILlari. (ed.), El hombre barroco, Madrid, Alianza, 1991.

Hispania Sacra, LX

122, julio-diciembre 2008, 635-658, ISSN: 0018-215-X 
"Contribuirá también mucho, renovándose la antigua costumbre que había, de salir todos los años a la Campiña, diferentes Misioneros a predicarles, instruirles y ponerles en el verdadero Camino de la ley de Dios y habiendo para este laudable fin dejado afincados en los bienes de los jesuitas el Ilte. Señor Dn. Cayetano Marcellano Agramont obispo que fue de esta diócesis seis mil pesos para que con sus réditos se costeasen dos misioneros que predicasen e instruyesen en la campiña todo el año como de facto lo hacían y se ha suspendido y omitido esta importante obra desde su expulsión por cuya causa se han seguido infinitos males»?.

Los cabildantes manifestaron que las misiones implicarían «un servicio importantísimo a Dios, al estado y al público» ${ }^{10}$ y destacaron su carácter de dispositivos de pacificación de las comunidades rurales. En 1790, ante un fuerte conflicto entre el Cabildo y el cura vicario en un pueblo de la Banda Oriental, el obispo propuso pedir una misión de religiosos para «calmar los ánimos». Esta situación se repitió a comienzos del siglo XIX, cuando el obispo Lué y Riega, durante su visita diocesana, pidió a los mercedarios que proporcionaran «a la mayor brevedad posible [...] cuatro religiosos de los existentes en el Convento Grande de Buenos Aires para hacer misiones en los pueblos de una y otra banda de esta diócesis» ${ }^{11}$.

Pero las misiones no se solicitaron sólo como «terapias de emergencia», ya que tanto mercedarios como franciscanos las practicaron con cierta regularidad en distintos momentos de la segunda mitad del siglo XVIII. Lo hicieron desde dos instituciones creadas específicamente para «ejercitar el santo ministerio»: el Hospicio o Colegio de Misioneros de San Ramón de Las Conchas de los mercedarios y el Colegio franciscano de Propaganda Fide de San Carlos de Carcarañá en Santa Fe. En ambos casos los misioneros, con estadías de una o dos semanas en cada parroquia, reforzaron la acción pastoral y sacramental de los párrocos, quienes con frecuencia se veían en problemas para atender a una población muy dispersa. Los ordinarios diocesanos promovían misiones y los párrocos -y parte de las feligresías cuya monotonía cotidiana se veía felizmente alterada- recibían a los misioneros con los brazos abiertos y luego daban unánime testimonio de los buenos frutos que habían producido.

En 1768 el obispo de Buenos Aires autorizó una misión de mercedarios con el objeto de absolver pecados, bendecir imágenes y oratorios y «demás que pida óleo sacro» como «revalidar los matrimonios nulos, contraídos por delito oculto, aunque haya habido malicia por parte de ambos contrayentes, legitimando la prole que tengan o en adelante tuvieren y para que puedan habilitar

${ }^{9}$ Archivo General de la Nación, Argentina (en adelante AGN)-AECBA (Acuerdos del Extinguido Cabildo de Buenos Aires), serie III, Tomo VIII, p. 674.

10 Ibidem.

11 AGN, IX-31-5-7 exp. 744 y Edgard STOFFel, Documentos inéditos de la Santa Visita Pastoral del Obispado del Río de la Plata, 1803 y 1805, Santa Fe, Universidad Católica de Santa Fe, 1992. 
a los incestuosos ad usum matrimonii ${ }^{12}$. Entre 1768 y 1769 estas misiones recorrieron las parroquias de San Isidro, Luján, Areco, San Nicolás, Baradero, Quilmes y Magdalena. El párroco Francisco de Cossio y Terán, certificaba las tareas de los misioneros en su paso por San Nicolás:

«oyendo sacramentalmente a mis feligreses e instruyéndolos con su buen ejemplo y apostólico celo de que ha resultado tan copioso fruto que han comulgado novecientas y tantas personas y se experimenta una general compunción en todos los asistentes, mucha mesura y moderación en sus tratos y demostraciones públicas de reconciliación en los mal afectos con lo que me prometo se haya logrado el exterminio de los vicios con particular reforma de las costumbres» ${ }^{3}$.

En esa misma ocasión, a su paso por Luján, los mercedarios desarrollaron una «teátrica misionera» ${ }^{14}$ que el párroco de la villa describió del siguiente modo:

"...haciendo al fin de ella un sermón, tan edificativo alentando a los fieles a la caridad con los pobres, y en especial con los cautivos cristianos, haciendo finalmente una procesión solemne con Nuestra Señora de las Mercedes en la cual personalmente pedían la limosna para el rescate de los cautivos, moviendo asimismo con tres niños que vistieron como cautivos a lo morisco con sus grillos y cadenas...»15.

Durante el mismo año de 1769 misionaron en Luján los franciscanos que se dirigían a Ocopa, en las provincias norteñas ${ }^{16}$. Durante su estadía los frailes intervinieron junto a otro religioso que oficiaba de teniente de cura en una disputa conyugal que involucraba nada menos que al alguacil mayor del cabildo local, Salvador Castellanos. En una verdadera operación de rescate, los frailes consiguieron sacarle la espada a Castellanos, sujetarlo y lograr que soltara a su esposa. La disputa incluyó la intervención del párroco como juez eclesiástico, una demanda por falta de respeto a los misioneros $-\ll$ Dn Salvador Castellanos, Alguacil Mayor de la Villa de Luján perdió el respeto a los tres Padres Misioneros de San Francisco que estaban en actual misión»-, al teniente cura y a su casa, y finalmente la destitución del alguacil del cabildo, que había desempeñado el cargo durante trece años. De manera que en sus estadías en cada parroquia

12 Archivo Histórico de la Provincia de Buenos Aires (en adelante AHPBA), Escribanía mayor de Gobierno (en adelante EMG) 13-1-1-6.

13 Ibidem, f. 27.

${ }^{14}$ Francisco Rico CALLADO, «La teatralidad en la predicación barroca: las misiones populares en la España de los siglos XVII-XVIII», en José AlCALÁ ZAMORA y José Belenguer (coords.), Calderón de la Barca y la España del Barroco, vol. 1, Centro de Estudios Políticos y Constitucionales. Sociedad Estatal España Nuevo Milenio, Madrid, 2001 pp. 549-563.

${ }^{15}$ AHPBA, EMG, 13-1-1-6, f. 29.

16 AHPBA EMG 13-1-1-5.

Hispania Sacra, LX

122, julio-diciembre 2008, 635-658, ISSN: 0018-215-X 
las tareas de los misioneros eran amplias y podían exceder las prácticas estrictamente sacramentales.

Los párrocos se mostraban a la hora de dar testimonio de los frutos y la convocatoria que había despertado la misión entre sus feligreses - «excesivo número de almas», «gran número de gentes»- y algunos, como el de San Nicolás, aventuraron cifras más que optimistas como las «novecientas y tantas personas» que acreditó el cura Cossio y Therán en la misión llevada a cabo en su parroquia.

El celo misionero no cesó. Los franciscanos volvieron a predicar misiones al cabo de dos décadas. Para ello les fue concedida por Real Cédula del año 1775 una estancia en Carcarañá, Santa Fe, que había pertenecido a los jesuitas. Allí fundaron el Colegio de Misioneros de San Carlos, desde donde organizaron misiones que recorrieron todas las jurisdicciones de la diócesis a lo largo de décadas ${ }^{17}$. Los franciscanos tomaron posesión de la estancia en 1780 y el Colegio comenzó a funcionar formalmente el 27 de julio de 1786 con los trece religiosos que componían la misión llegada desde España. Estas instituciones dedicadas a la reforma de costumbres de los fieles y a la conversión de infieles, funcionaron como dispositivos específicos para el apostolado en ciudades y campiñas. Se celebraban anualmente. El Cabildo de Santa Fe, en su informe y solicitud al Rey de 1774, explicó que el objetivo de la institución era

«el bien espiritual de aquellos vecinos y moradores no sólo del distrito de dicha estancias, sino a todo lo restante de los curatos de la campiña de esta Gobierno y Provincia del Paraguay y Tucumán, que están sin inmediatos Párrocos que les administren el pasto espiritual por haber de esparcir los religiosos a todos estos lugares para la predicación evangélica y reformación de costumbres [...] La dicha fundación aunque no está del todo inmediata a las fronteras del Gran Chaco, donde se hallan las más numerosas naciones de infieles, pero puede servir de mucho provecho a otros indios de aquellas circunferencias como también a españoles y patricios que están poblados en aquellos parajes, careciendo de pasto espiritual, que tendrán por medio de los misioneros que se establezcan en aquel Colegio. Se aumentarán las poblaciones y se propagará el santo Evangelio» ${ }^{18}$.

${ }_{17}$ Cayetano Bruno, Historia de la Iglesia en la Argentina, Buenos Aires, Don Bosco, 1970, Vol. VI, pp. 379-383; Teófilo PinILlos, Historia del Convento de San Carlos de San Lorenzo, Buenos Aires, 1949; Pedro Borgés Morán, El envío de misioneros a América durante la época española, Salamanca, Universidad Pontificia, 1977. AGN-AECBA, serie III, Tomo VIII, p. 673. AGN, IX-31-5-3, exp. 623, AGN, IX-21-8-2 exp. 12. «Real Cédula del Rey Carlos III aprobando la concesión de la Iglesia de la estancia de San Miguel para un Colegio de Misioneros franciscanos. Año 1775», en Nuevo Mundo, 3-4 (2002-2003) pp. 71-72.

${ }^{18}$ Archivo del Convento de San Lorenzo, Documentos sobre la fundación del Colegio de San Carlos, Legajo No 1, cit. por Teófilo Pinillos, Historia del Convento de San Carlos de San Lorenzo, Buenos Aires, 1949, pp. 13-14) 
Las misiones eran la estrategia más conveniente en una campiña «tan poblada y apartada de las parroquias», donde:

«por la mayor necesidad de pasto espiritual, como porque la reciben generalmente con afecto sencillo en fuerza del cual las verdades evangélicas encuentran menos embarazo en la fe ciega de sus moradores, haciendo en ellos por esta razón una impresión extraordinaria que sin demora los reduce a la ley» ${ }^{19}$.

Las misiones fueron nuevamente autorizadas. Consta que se realizaron en todas las regiones de la diócesis (excepto las reducciones de indios ${ }^{20}$ ) en los años 1786 (oeste y norte de Buenos Aires, Santa Fe y Banda Oriental), 1787 (Entre Ríos y Banda Oriental), 1788 (norte de Buenos Aires y Santa Fe), 1789 (cercanías de la ciudad de Buenos Aires y Río Tercero en la frontera cordobesa), 1790 (frontera norte y sur de Buenos Aires), 1791 (Corrientes) y 1793 (Banda Oriental y Buenos Aires). Esto demuestra que se trató de una práctica sistemática. Los misioneros realizaban sus actividades en las parroquias y oratorios y en las capillas de los fuertes de la frontera. En 1788 el Dr. Dn Francisco Antonio de Vera Muxica, cura rector de la Iglesia Matriz de la ciudad de Santa Fe, describió los resultados de las misiones afirmando

"que el ejemplo de humildad, modestia, religiosidad y particular constancia y esmero al confesionario de estos apostólicos operarios de la viña del Señor ha causado en todo el pueblo una justa idea de su virtud, que en mi juicio ha contribuido no poco al general aprovechamiento de las almas ya que con frecuencia insten mis feligreses no les prive de este beneficio espiritual todos los años $»^{21}$.

Recogiendo la experiencia de las misiones predicadas durante varios años, al menos desde 1788, los frailes escribieron en 1792 un «Ceremonial de las misiones» que pauta las actividades de los misioneros ${ }^{22}$. Se especifican en el texto las distintas actividades prescriptas durante la misión y el modo de realizarlas: Del tiempo de salir a Misión y de los que debe preceder a las salidas, De lo que deben llevar los PP Misioneros, Del modo de proceder entre sí mismos los PP. Misioneros y delante de los seglares, De la Salida del Colegio, de los Viajes y el modo de proceder en las Casas donde se hospedan los Misioneros, etc. ${ }^{23}$.

Este Ceremonial, de factura local, recoge a la vez las pautas más o menos generales de las misiones interiores dentro de la orden y los rasgos particulares

19 AGN, IX-31-3-1 exp. 50.

${ }^{20}$ Este Colegio de misioneros se iría haciendo cargo a partir de 1797 de distintas reducciones de indios del norte de Santa Fe.

${ }^{21}$ AGN, IX-31-5-3, exp. 623, f. 37. El destacado es nuestro.

22 «Ceremonial de las misiones del Colegio Apostólico de San Carlos del Carcarañal. Año 1792», en Nuevo Mundo, 3-4 (2002-2003), pp. 99-124.

23 «Ceremonial de las misiones....» cit., p. 99.

Hispania Sacra, LX

122, julio-diciembre 2008, 635-658, ISSN: 0018-215-X 
que podía asumir la práctica en una región particular. A través del ceremonial conocemos algunas de las tareas preparatorias, como las más básicas de tramitar la autorización del obispo de la diócesis, confeccionar el Itinerarium Clericorum y preparar sermones y doctrinas. Aunque se consideraba conveniente que todos los misioneros llevaran «impuesta y estudiada» la misión completa, los sermones se distribuían entre los frailes «atendiendo a los genios y prendas naturales de que cada uno se halle dotado; pues es constante que algunos hacen prodigios con un Sermón del Infierno; y con un Sermón de Gloria no lo hacen» ${ }^{24}$.

Para esas «apostólicas expediciones» los misioneros portaban «armamento y avío espiritual»: el Divino Crucifijo, tablas con sus rejillas para armar confesionarios para mujeres, una campanilla y una banda morada, disciplinas, estampas, cuadernos, obleas y tintero, Breviario, Kalendario y otros libros ${ }^{25}$.

Debían atender asimismo a una serie de recomendaciones relativas a sus comportamientos durante la misión: respetar el orden de precedencia entre los padres misioneros, guardar el sigilo sacramental, evitar discusiones delante de los feligreses, evitar visitar sus casas, entre otras. Antes de salir a la misión se acostumbraba enviar una nota al párroco del primer pueblo al que llegarían, informándolo la fecha de arribo y solicitándole que fuera previniendo a sus feligreses de la misión y los exhortara a la puntual asistencia a sus «sagradas funciones». Como la mayoría de éstas se realizaban de noche, o «un poco antes de ponerse el sol», también solicitaban la ayuda de las autoridades civiles de cada paraje para que una patrulla vigilara el pueblo y controlara que las pulperías y canchas de bolas se encontraran cerradas.

La misión se iniciaba habitualmente durante la semana de Cuasimodo u Octava de Pascua, que durante mucho tiempo constituyó una suerte de prolongación de la fiesta de Resurrección. El fin principal de las misiones se orientaba a convertir pecadores a penitencia, mediante la confesión y la comunión general. Era la oportunidad de ganar Santos Jubileos o indulgencia plenaria al cabo de varios días de preparación escuchando sermones y doctrinas y haciendo penitencias.

En las funciones solían intervenir el párroco y el maestro de escuela. Sólo los últimos días tenían lugar las confesiones generales, precedidas por una práctica denominada «Sermón de los enemigos», un ritual de reconciliación entre personas que se hallaban enemistadas. El «Sermón de los enemigos» ocupa-

\footnotetext{
24 «Ceremonial de las misiones...» cit. p. 101. Los primeros días los sermones eran: $1^{\circ}$. de la Misericordia; $2^{\circ}$. de no dilatar la Penitencia, $3^{\circ}$. de la Gravedad del Pecado; $4^{\circ}$. de la Integridad de la Confesión; $5^{\circ}$. del Dolor y Propósito.

${ }^{25}$ La Teología Moral del Ilustrísimo Ligorio, un juego de Echarri Ilustrado, el Manojito de Tellado; la Aljaba de las Saetillas y el Librito de los Versos de la Pasión, en «Ceremonial de las misiones...», p. 102 .
} 
ba un lugar importante dentro de la misión, dado que la pacificación de las feligresías era un objetivo central de las misiones. El Ceremonial del Colegio de Carcarañá pautaba la realización de esta práctica y buscaba con distintos argumentos evitar que los participantes pidieran el perdón en público: «por la gran confusión y alboroto que ocasiona el buscarse unos a otros en la Iglesia», "porque si la ofensa que se han hecho es oculta, no están obligados a dar pública satisfacción» y finalmente "porque nos exponíamos a que el perdón se hiciere de ceremonia y no de corazón». Por ello establecía pasos muy prolijos para este ejercicio de la reconciliación entre vecinos: «el que hubiese injuriado u ofendido a alguna persona, irá a buscar a su casa (o carreta) y en llegando dirá La Paz de Dios sea en esta casa y responderán de adentro, $\underline{\text { Amen }{ }^{26}}$.

Los días de confesiones los frailes se levantaban muy temprano, realizaban sus ejercicios espirituales (oración mental, recitación de las horas menores y celebración de la misa), confesaban luego toda la mañana -alternando hombres y mujeres, estas últimas en confesionarios con rejilla-, almorzaban, dormían la siesta y al levantarse volvían a rezar, tomaban mate y retornaban al confesionario hasta la misa de la tarde.

Los frailes prevenían que desde el segundo día de la misión todas la noches «habrá Disciplina aquí en la Iglesia, después de la Misión, con solos los hombres, y así vengan prevenidos con sus azores o guascas los que quisieran castigarse». Invitaban además a hombres y mujeres a que se confesaran con su párroco, porque «todos los confesores son buenos y tal vez mejores que nosotros y tienen las mismas facultades». Es probable que por aburrimiento o por desconfianza los feligreses evitaran la confesión con un eclesiástico tan cercano y de trato cotidiano como lo solía ser su cura párroco. Como abundaban los casos de violación de sigilo sacramental, el mismo Ceremonial dedicaba una recomendación para recomendar su respeto:

«no referir cuentos o chistes oídos en confesión, pero en especial delante de los Legos para evitar el escándalo de Pusilos, que no pocas veces se sigue de semejantes conversaciones con grande perjuicio de las Almas. Y aún para consultar entre sí mismos los casos de conciencia deben usar de mucha cautela proponiéndolos muy en abstracto».

Como en el caso de los mercedarios, los párrocos certificaban las tareas desarrolladas durante la misión en la enseñanza de la doctrina, la predicación del Evangelio y las confesiones. Manifestaban por ejemplo que «la misión se concluyó con conocido frutos y universales aplausos de pueblo y con admiración de su ejemplarísima conducta religiosa» ${ }^{27} \mathrm{o}$ «que los frailes estuvieron en su

26 «Ceremonial de las misiones....» cit. pp. 117-118.

${ }^{27}$ AGN, IX-31-5-3, exp. 623, f. 12. Certificación del párroco Sebastián Quesa de Colonia del Sacramento, Real de San Carlos y Rosario del Colla.

Hispania Sacra, LX

122, julio-diciembre 2008, 635-658, ISSN: 0018-215-X 
parroquia anunciando a todos mis parroquianos la doctrina de Jesucristo con aquella energía, claridad y celo propios de su ministerio como se deja ver por los efectos tan admirables que han resultado en mis amados feligreses» 28 . El párroco de Víboras en la Banda Oriental aprobaba con entusiasmo el resultado de la misión: "De aquí resultó universal aprovechamiento de estas almas, el que he experimentado como pastor que soy de ellas, reconociendo una reforma tal de costumbres que jamás conocí en estas gentes en el dilatado tiempo que sirvo en esta parroquia» ${ }^{29}$.

En suma, durante el período borbónico las misiones interiores, inauguradas en la región por los jesuitas, cobraron renovada vigencia gracias a los nuevos colegios de misioneros establecidos ad hoc. Obispos, cabildos y párrocos encontraron en la acción de los misioneros respuestas a diferentes problemas: los prelados apelaron a ellas como un instrumento de pacificación, los cabildos las vieron como una herramienta para el ordenamiento de la vida rural y los párrocos encontraron en ellas una ayuda para llevar a cabo las más básicas de sus tareas pastorales, por lo que podemos afirmar que en este plano se verificó una activa e intensa colaboración entre el clero secular y el regular.

\section{LAS «MISIONES FEDERALES» DE LA DÉCADA DE 1830}

Con Rosas las misiones volantes volvieron a recorrer la campiña porteña. El mismo mes en que fue designado gobernador, se ordenó el 29 de diciembre de 1829 al provisor del obispado que preparara tres misiones a distintos puntos de la campiña que no se especificaban y se le indicaba que se prestarían gustosos a realizarla los padres franciscanos. En enero de 1830 se reiteraba al provisor la orden de que «prepare tres misiones para la campiña», y el 6 de abril de 1830 la Comisaría de Guerra firmaba un contrato con tres individuos para que se hicieran cargo del manejo del carruaje «que conduce al Norte una misión de Religiosos Franciscanos». Una carta de Fr. José Nicolás Lacunza a José María Zelaya, que se conserva adjunta, informa sobre el desarrollo de la misión, que recorrió los partidos de Baradero y San Pedro entre los meses de junio y septiembre ${ }^{30}$.

Pero fue durante el segundo gobierno de Rosas que las misiones adquirieron mayor repercusión, en razón de la creciente desconfianza que desarrolló a partir de entonces Rosas en relación al clero secular, tras haber detectado un cierto número de sacerdotes disidentes o decididamente unitarios. En particular el ca-

\footnotetext{
${ }^{28}$ Ibidem, f. 16. Certificación del párroco José Basilio López de Concepción del Uruguay.

${ }^{29}$ Ibidem, f. 18. Certificación del párroco Antonio Mariano Alonso de la Parroquia de Víboras.

${ }^{30}$ AGN, X-4-8-6, Culto 1827-1830.
} 
bildo eclesiástico, liderado por figuras demasiado comprometidas con un reciente pasado unitario, indujo al gobernador a apostar por la autoridad del dócil obispo Mariano Medrano y a reconstituir el clero regular desmantelado durante la reforma. De ahí la política de apoyo sistemático a la lucha de Medrano contra el cabildo y la promoción de los franciscanos, a los que permitió reabrir el noviciado y devolvió los edificios que habían pasado a la Universidad, el regreso de los dominicos, el frustrado proyecto de retorno de los recoletos y sobre todo el de los jesuitas, que se concretó en agosto de $1836^{31}$.

La escasez de clero por un lado, y por otro la desconfianza en relación a nombrar párrocos que, una vez obtenido el curato en propiedad, ería difícil remover, indujeron a Rosas a convocar a las misiones volantes de franciscanos y jesuitas. Sobre las primeras tenemos muy pocas noticias, ninguna de ellas confirma que realmente se hayan concretado luego de 1835. Las de los ignacianos, en cambio, encontraron amplio eco en la controladísima prensa periódica y lograron amplio impacto en las parroquias visitadas. Un documento extraordinario para conocer el desarrollo de estas misiones es el De sacris expeditionibus initis per Diocesim Bonaerensem [1837-1838], redactado por el superior Mariano Berdugo. A diferencia de otras producciones del extendido género literario misional, elaborado principalmente bajo la forma de cartas, este texto fue más bien un informe a los superiores. Está redactado en latín, lo que descarta el propósito de difundirlo fuera de la Compañía.

Según el documento, las tareas más inmediatas que el gobernador pensaba asignar a los jesuitas redivivos eran la educación de la juventud y las misiones ${ }^{32}$. Fue en efecto Rosas, no el obispo, quien decidió en cada caso qué pueblos y parroquias se visitarían y quien estableció las modalidades de cada misión. En carta del 1 de septiembre de 1837, tras explicar al gobernador que entre el 20 y el 25 de ese mes debería salir la misión para poder comenzar los trabajos a principios de octubre, Berdugo le aseguraba que haría lo posible para que fueran efectivamente tres los misioneros enviados y que se detendrían en cada pueblo el tiempo necesario "para que el fruto sea mas duradero y sólido», en términos que sólo cobran sentido como respuesta a una carta perdida o a una recomendación verbal de Rosas para que se obrase así. Además, Berdugo le pedía explícitamente a Rosas y no al obispo que determinara qué parroquias iban a visitar: «Necesito saber

\footnotetext{
${ }^{31}$ Roberto DI STEFANO, «El laberinto religioso de Juan Manuel de Rosas»..., cit.

32 «Marianus Medrano Cabrera Bonaërensis dioceseos Antistes una cum Joanne Emmanuele Rosas reipublicae administrandae praefecto a Societatis Patribus vehementius expectierant, non modo ut juventutis ad bonas artes instituendae curam susciperent, verum universae, etiam reipublicae provincias sacris expeditionibus excolerent, donec omnia, quae ad christianam Indorum institutionem erant idonea, pararentur.». El documento en Archivum Historicum Societatis Iesu (en adelante ARSI), Arg-ch 1001-II, 4. Cfr. También ARSI, arg-ch, 1001, III, 6: Carta de Cesáreo González a Francisco Javier de Lara, Buenos Aires, 19 de agosto de 1836.
}

Hispania Sacra, LX

122, julio-diciembre 2008, 635-658, ISSN: 0018-215-X 
la ruta de los pueblos, que V.E. juzga mas conveniente, y que se sirva favorecernos con algún billete de recomendación para las autoridades de ellos, ya que espero me lo proporcione el Sr. Obispo para los Curas».

La carta revela, por otra parte, que la tarea de organizar las misiones implicaba cautela y que por tanto la preparación debía realizarse con reserva, sin duda por motivos políticos. Por eso Berdugo pedía a Rosas que «hasta el punto de verificarse [la misión]» se le diera «la menor publicidad posible» y que sería prudente que las instrucciones no se enviaran por escrito ${ }^{33}$. El 14 de septiembre se redactaron las instrucciones de Rosas para ser enviadas a Berdugo, junto con los pasaportes de los misioneros. En ellas se indicaba que las parroquias a visitar serían las del norte de la provincia, pero no todas, sino sólo aquéllas que por su ubicación permitieran la concurrencia de las feligresías de los alrededores. Las motivaciones eran fundamentalmente políticas:

«...en todos los puntos indicados no faltan algunos impíos unitarios enemigos de la Religión Santa del Estado, aunque hoy porque mas no pueden, ocultos vestidos con la máscara que conviene a sus logias infernales. Que la masa general, y con especialidad los Pobres con muy contadas excepciones son Federales y de consiguiente firmes en la fe de Jesucristo. Que en el mismo caso se hallan las gentes de la campiña de San Isidro, San Nicolás de los Arroyos, y de San Antonio de Areco, pero que no sucede así con los vecinos de posibles de pueblecitos de estos partidos, donde la cuarta parte de esos vecinos de posibles son unitarios impíos logistas, encubiertos algunos con la capa de federales; que, por lo tanto, si en todos los puntos donde pare la misión conviene predicar los evangelios de Cristo, las ventajas de nuestra Santa Causa Federal y demás máximas sólidas de virtud y moral que atacan la impiedad y conducen las personas a la senda de la gloria verdadera, en San Isidro y San Nicolás es donde desearía S.E. que lo fuese con la detención que demandan los extravíos de algunas almas que han conseguido corromper las tentaciones del demonio...»34.

Rosas consideraba que sus enemigos ocultos se encontraban primordialmente en los pueblos más grandes y entre «los vecinos de posibles». La predicación de los misioneros debía concentrarse en esos pueblos, en particular en los más grandes como San Isidro y San Nicolás, donde era más necesaria la predicación misionera, evangélica y política. Esos deseos de Rosas se vieron secundados por una circular que el obispo Medrano dirigió a los curas, en la que sostuvo que no había «nada más justo que el clero conforme sus opiniones con las del

33 AGN, X-4-9-4, carta de Berdugo a Rosas de 1 de septiembre de 1837.

34 Culto 1835-1851, AGN, X-4-9-4, instrucciones del 14 de septiembre de 1837. F. C. ACTIS, Historia de la Parroquia de San Isidro y de su Santo Patrono, 1730-1930, s.1., Institución Juan Segundo Fernández, s/f, p. 163. No se entiende por qué Actis asegura que los jesuitas realizaron las misiones «sin ajustarse por supuesto a las curiosas indicaciones del Restaurador», afirmación que se reproduce sin discusión en J. A. Lavalle, A. N. Manfredi (h) y P. André de Shaw Strada, San Isidro punzó, San Isidro, Municipalidad de San Isidro, 2005, p. 147. 
Superior Gobierno» y que «cualquier disidencia en esta parte pudiera ser ruinosa al Estado y perpetuar males que a todos nos serían sensibles, y que una dilatada experiencia nos ha hecho sentir con dolor». La generalización del uso de signos externos de adhesión a Rosas debía dar como resultado la abolición de la moda de los «logistas», que usaban ropa almidonada con agua de añil para que con el paso de los días tendiese al «celeste claro». La conducta del párroco debía ser severa en el control de las expresiones cromáticas: luego de reconvenir a los que se mostraran indiferentes a las exhortaciones «por dos o tres ocasiones», se les haría entender en última instancia que a los renitentes «se les prohibirá la entrada a la Iglesia para cuyo efecto se pondrá Ud. de acuerdo con el Juez de Paz de ese departamento» ${ }^{35}$.

Volviendo a la ruta de las misiones, vale la pena señalar que los planes iniciales se vieron modificados por las «instancias» de las autoridades y feligresías de los pueblos que no serían en principio visitados. También esos pedidos se elevaban no al obispo sino a Rosas, quien los dirigía luego a los jesuitas que ya estaban llevando a cabo la misión. Así, el 5 de octubre de 1837 Berdugo acusó recibo del «oficio de V.E. en el que le remite la solicitud del vecindario federal de San Fernando, para que pase allá la santa misión, y en que V.E. le significa sus deseos de que sean atendidos sus votos.» El cambio de planes fue aceptado, y la visita de San Fernando se estableció para la siguiente semana, con el fin de «que su federal vecindario quede servido, y obedecidos los deseos de V.E.».

En otras ocasiones la solicitud era dirigida directamente a Berdugo, quien consultaba a Rosas (no al obispo) pidiendo instrucciones. El 6 de noviembre, desde Exaltación de la Cruz, Berdugo informó a Rosas que «... se ha recibido un oficio del Sr. Juez de Paz del Baradero, haciendo las mas vivas instancias para que la abriésemos allí, interesándose en ello todo el vecindario» ${ }^{36}$. Que la institución eclesiástica diocesana carecía absolutamente de autonomía en el despliegue de estas «expediciones apostólicas» queda claro a cada paso en la lectura de las fuentes. No sólo Rosas estableció el itinerario, las modalidades de la misión y el contenido de las predicaciones; no sólo Berdugo escribía a Rosas y no al obispo solicitando autorización para visitar los pueblos que no habían sido incluidos en el plan primigenio: además era Berdugo y no el obispo Medrano quien rogaba a Rosas que permitiera al obispo de Aulón, Mariano José Escalada, a quien el gobernador no veía con buenos ojos, que se sumara a la misión para administrar la confirmación ${ }^{37}$. Y era a Rosas y no a Medrano a quien

\footnotetext{
${ }^{35}$ Francisco ACTIS, Historia de la Parroquia de San Isidro..., cit, p. 163.

${ }^{36}$ De sacris expeditionibus..., f. 9: «Iam inde enim a multis mensibus spirituali auxilio erant destituti propter gravissimam et diutiurnam aegritudinem, qua Parrochus vexabatur».

${ }^{37}$ AGN, X-4-9-4, Culto 1835-1851, carta de Berdugo a Rosas, Exaltación de la Cruz, 6 de noviembre de 1837: «Con esta ocasión, señor no puedo menos de significar a V.E. cuanto interesa la misión en la administracion del Sto Sacramento de la Confirmación, que no pudiendo administrar el Iltmo Sr Obis-
}

Hispania Sacra, LX

122, julio-diciembre 2008, 635-658, ISSN: 0018-215-X 
Berdugo se atrevía a solicitar que tomara medidas para dotar de curas las parroquias vacantes que habían sido visitadas, expresándole su pena:

«... al dejarlos en tanta escasez de sacerdotes, los cuales cultivando lo que se siembra [con la misión], tendrían el consuelo de verse no ya en medio de gente dócil, sino de un pueblo santo. $Y$ a este efecto, Señor, V.E. me dispensará, que le suplique con todo el ardor posible, y de que soy capaz, vea como en cada uno de ellos pueda haber uno o dos, que dirijan tan bellas almas.»

El 15 de noviembre, una nota firmada por «MC» (Seguramente Manuel Corbalán) aprobó en nombre de Rosas la propuesta de Berdugo de visitar Baradero y la de sumar a Escalada a la misión para que administrase la Confirmación, pero el nombramiento de curas era decididamente denegado:

«En orden a los Sacerdotes que faltan en algunos Pueblos de campiña bien lo sabe, $y$ lo tiene S.E., sobre su corazón; pero agrega que no basta desear las cosas mas precisas para conseguirlas u obtenerlas a satisfacción de modo que el remedio no sea peor que el mal. Que poco a poco se va adelantando, y poco a poco con el favor de Dios nuestro Señor todo se ha de ir remediando».

Rosas se mostraba decidido, en esa coyuntura, a no correr el riesgo de llamar a concursos para cubrir las parroquias vacantes, sin duda a causa del peligro que comportaba el que pudieran eventualmente ser promovidos a ellas sacerdotes poco dóciles. Si tenemos en cuenta la negativa del cabildo eclesiástico a la solicitud de Rosas de otorgar la propiedad a los curas interinos obviando el llamado a concurso, queda claro que las misiones se perfilaban como el mecanismo más seguro para pacificar y concitar consensos en la campiña ${ }^{38}$.

¿Qué modalidades concretas adquirían estas misiones? El momento más oportuno para realizarlas era el que mediaba entre septiembre y enero, cuando empezaba a ceder el frío, los lodazales de los caminos se secaban y los campesinos se encontraban en un momento del calendario agrícola que les consentía una relativa calma, porque ya había concluido la siembra y no había llegado aún el momento de la cosecha. Así, los jesuitas que misionaban en 1837 planearon interrumpir sus actividades a fines de diciembre porque «la gente del campo estará ocupada en la siega hasta principios de Mar-

po diocesano, ha comisionado al Iltmo Sr Escalada, como sin duda sabrá V.E. [...] Por mi parte Señor, viendo logrados mis deseos en el mayor bien de las almas; me falta saber, si, como del celo de V.E. lo creo, es de su superior aprobación y por tanto me atrevo a suplicarle, se sirva indicármelo para que sea completa la satisfacción que me cabe en emplear nuestros cortos talentos en beneficio de la Campiña».

38 Rosas solicitó al cabildo que otorgara la propiedad a los curas «confiables» sin la mediación del concurso en 1830: cfr. La carta de Rosas al provisor fechada en San Nicolás de los Arroyos el 29 de Abril de 1830 en AGN, X-23-9-4. Secretaría de Rosas, 1830. 
$z o » 39$. En el caso de las misiones de la Compañía, el núcleo del personal comprometido lo constituyeron tres sacerdotes -el superior Mariano Berdugo, el predicador Francisco Majesté y el Padre Miguel Cabezas-, a los que en algunos tramos se sumaron el obispo de Aulón Mariano Escalada y otros sacerdotes del clero secular de la ciudad. Por otra parte, en cada parroquia colaboraba el párroco, cuando lo había, y con frecuencia otros sacerdotes residentes dentro de los términos del curato y a veces los curas de las parroquias vecinas ${ }^{40}$. En San Fernando los jesuitas recibieron la ayuda del cura interino del pueblo, Tomás Gomensoro, del párroco de San Isidro, Cipriano Gonelli -que los había acompañado ya en su propia parroquia- y la de los presbíteros Francisco Ferreira de la Cruz, José Antonio Picazarri y José Letamendi ${ }^{41}$.

La misión era acogida con el mayor boato posible: los vecinos más «respetables» salían a recibir la carroza de los misioneros en la frontera del curato, hasta donde habían sido escoltados por los vecinos «más notables» del que los despedía, y luego los acompañaban hasta las puertas del pueblo, donde los esperaban el cura con la cruz parroquial y el resto de los feligreses, tal vez enarbolando estandartes con la imagen de la Virgen. Así por ejemplo, el relato del De sacris expeditionibus describe el recibimiento en San Fernando por parte del vicepárroco, Francisco Ferreira, y de «todo el pueblo», con solemne pompa y llevando el crucifijo a la cabeza ${ }^{42}$. A veces los visitantes eran agasajados antes de llegar al núcleo urbano, como en San Pedro, donde se recibió a Escalada y a los jesuitas con un suculento asado con cuero en una estancia ${ }^{43}$. Se intentaba que todos los pasos del ritual del recibimiento quedaran grabados en la memo-

${ }^{39}$ ARSI, Arg-ch. 1001-IV, 13: «Copia de una carta del P. Bernardo Parés al P. José de Jáuregui», Buenos Aires, 20 de noviembre de 1837.

${ }^{40}$ El juez de paz de San Isidro a Rosas, San Isidro, 14 de octubre de 1837, en La Gaceta Mercantil, 16 de octubre de 1837: «Cree el infrascrito que /.../ faltaría a un deber de justicia sino elogiase debidamente el celo con que ha cooperado a esta Santa Misión el respetable Cura Vicario de esta Parroquia, pudiendo decirse que por su asidua asistencia al confesionario ha trabajado a la par de los PP. Misioneros. También han prestado interesantes servicios los Sres. Presbíteros D. Francisco Ferreira de la Cruz y D. Narciso Mansilla residentes en este Pueblo, y últimamente al Sr. Presbítero D. José Antonio Picazarri, que en el coro, y confesionario ha contribuido al decoro de las funciones y consuelo de los fieles». La restante información sobre la visita a San Isidro, salvo indicación contraria, proviene de la misma fuente.

${ }^{41}$ El juez de paz de San Fernando a Rosas, San Fernando, 2 de noviembre de 1837, en Gaceta Mercantil, 4 de noviembre de 1837. La restante información sobre la visita a San Fernando, salvo indicación contraria, proviene de la misma fuente.

${ }^{42}$ De sacris expeditionibus..., f. 9: «Ipsa pagorum proximitas pium obtulit spectaculum quod est duriores emollevit. Statim ac cum presbytero Francisco Ferreira, qui tunc vices parochi agebat, totum Sancti Ferdinandi viderunt nostri populum solemni pompa cum imagine Crucifixi procedentem...».

${ }^{43}$ El juez de paz de San Pedro a Rosas, San Pedro, 21 de diciembre de 1837, en La Gaceta Mercantil, 26 de diciembre de 1837. La restante información sobre la visita a San Pedro, salvo indicación contraria, proviene de la misma fuente.

Hispania Sacra, LX

122, julio-diciembre 2008, 635-658, ISSN: 0018-215-X 
ria de los presentes por medio del despliegue del mayor esplendor que consintiesen los recursos disponibles. Por ejemplo, antes de entrar en San Pedro los religiosos fueron recibidos junto al río Arrecifes por un numeroso cortejo de jinetes y de carrozas que los acompañaron al pueblo, donde las calles estaban adornadas con arcos de flores y ramas de sauce, amén de las cintas y carteles federales ${ }^{44}$. Recepción similar, con toda pompa, los esperaba en San Isidro ${ }^{45}$.

El párroco otorgaba su consentimiento para la realización de las actividades propias de la misión delegando la cruz parroquial, símbolo del mandato pastoral, al superior jesuita, responsable de la misión. Normalmente la permanencia en cada pueblo era de entre diez y quince días, si bien en algunos casos, como en San Nicolás de los Arroyos, podía llegar a extenderse a un mes. La duración dependía de la entidad demográfica del pueblo, pero también de la continuidad que hubiera caracterizado a la atención pastoral, principalmente a la presencia o ausencia de párroco. Pero no siempre: podía suceder que aunque hubiera cura los jesuitas consideraran la parroquia vacante en la práctica, a causa de las limitaciones del sacerdote que la administraba. El de San Pedro, en particular, les dejó una pésima impresión ${ }^{46}$.

Durante la misión los visitantes se ocupaban principalmente de confesar, enseñar la doctrina a niños y adolescentes, dirigir el rezo del Rosario y predicar. Las dos actividades fundamentales eran la confesión, a la que dedicaban la mitad del día, y la predicación, que se realizaba al caer de la tarde, cuando la concurrencia de público era mayor. Con la primera de estas dos prácticas se obtenía una relación estrecha y personal con el penitente, mientras con la segunda se buscaba el efecto emocional que la elocuencia del predicador era capaz de despertar en el ánimo de la multitud reunida ${ }^{47}$. El De sacris expeditionibus consigna el cronograma de las actividades realizadas cotidianamente en San Isidro, que podemos suponer fue aplicado en los demás pueblos. Las actividades, que comenzaban antes del alba, comprendían momentos de meditación de los misioneros, celebraciones eucarísticas, confesiones y otras prácticas devocionales y formativas ${ }^{48}$. En San Fernando, caída la tarde:

\footnotetext{
${ }^{44}$ De sacris expeditionibus..., f. 16.

${ }^{45} \mathrm{El}$ juez de paz a Rosas, 14 de octubre de 1837, en La Gaceta Mercantil, 16 de octubre de 1837.

${ }^{46}$ De sacris expeditionibus..., f. : «Gratos inter flores difficile non fuit nostris molestas spinas videre, jamque eorum animis persuasum erat, laboriosissimam futuram missionem. Multis enim annis sine Parocho fuerant; recensque, et advena vix idioma callebat».

${ }^{47}$ A. Rubial GarCía, La santidad controvertida, México, FCE, 1999, pp. 271-276.

${ }^{48}$ De sacris expeditionibus..., f. 4.: «Tempus in hunc modum fuerat distributum: hora quarta surgebat nostri, et ad quintam cum dimidio meditationem de more protrahebant; post meditationem unus missae sacrificium offerebat, et alii confessiones usque ad meridiem excipiebant; nulla vel per brevis admittebatur salutatio aut collocatio de rebus ab expeditione alienis, publice enim monitum fuerat ne cum tempus non suppeteret ad spiritualia officia illus moleste ferret, si praesto ceteris rebus esse non poterant: inmensa caput aliquod de Imitatione Christi ac contemptu mundi legebatur: reliquum tempus
} 
«a la doctrina seguía el santo Rosario, después la Plática doctrinal y moral; y en seguida, el recuerdo devoto y piadoso a las cinco sagradas llagas de Jesucristo, concluyendo con un elocuente Sermón, teológico y moral, alusivo a los diez Mandamientos del decálogo, preceptos de nuestra Santa Madre Iglesia, y deberes del hombre en Sociedad» ${ }^{49}$.

Porque la misión federal se concebía, al igual que las coloniales, como instrumento de pacificación, pero -y he aquí una novedad- a la vez como restauración del orden moral, político y religioso que las turbulencias de la revolución y la guerra habían puesto en crisis y cuya recuperación los párrocos no podían garantizar. La «restauración de las leyes» que puso fin a la aventura unitaria se completaría repristinando los valores perdidos a lo largo de más de un cuarto de siglo de convulsiones ${ }^{50}$. De ahí que uno de los objetivos de los misioneros fuera devolver la concordia a las familias, que constituían desde su punto de vista la base de la sociedad y al mismo tiempo una figura de la armonía general. Es significativo el acento que las autoridades eclesiásticas y civiles ponían en este punto. El juez de paz de San Fernando declara que los jesuitas:

"...han cooperado a unir todos los matrimonios que estaban desunidos, y casar todos los que estaban viviendo escandalosamente; a ensanchar y ratificar la opinión Federal de este vecindario, demostrando moralmente los indecibles bienes que ha proporcionado a todos los estados en general. Ellos han edificado los espíritus de este vecindario en las sagradas máximas de nuestra religión santa...» ${ }^{51}$.

El de San Nicolás de los Arroyos certifica que el obispo Escalada «ha desobligado a infinitos infelices, ha unido algunos matrimonios, y ha hecho se casen infinitos, que vivían escandalosamente» ${ }^{52}$. Fieles a las pautas literarias del género misionero, los documentos ponen de relieve a cada paso la masividad de la participación en cada una de las actividades: en San Pedro se extienden por trece días completos las confesiones multitudinarias de los más variados tipos sociales y étnicos. Con el resultado de que «multa matrimonia prave inita, rite

piis colloquiis transigebant. Vespere officio divino persoluto, lectione spirituali habita, iterum in ecclesiam prodibant, et dum unus e suggestu concionem habebat, auditorium pars animum aliis patribus in Ecclesia Sacrario aperiebat, pars sese ad id parabant».

${ }^{49} \mathrm{El}$ juez de paz a Rosas, 2 de noviembre de 1837, en La Gaceta Mercantil, 14 de noviembre de 1837. Subrayado mío.

${ }^{50}$ No sólo los jesuitas atribuyen a la revolución el deterioro de las costumbres y la crisis de las creencias religiosas tradicionales. También eclesiásticos criollos como, entre muchos otros, el obispo Escalada: cfr. su «Sermón predicado en la Iglesia de San Ignacio por el Ilmo. Sr. Obispo de Aulon... día 6 de Noviembre de 1836», en ARSI, Arg-ch 1001-III, 16.

${ }^{51}$ Ibidem.

${ }^{52}$ El juez de paz de San Nicolás de los Arroyos a Rosas, 20 de enero de 1838, en La Gaceta Mercantil, 29 de enero de 1838. La restante información sobre la visita a San Nicolás de los Arroyos, salvo indicación contraria, proviene de la misma fuente.

Hispania Sacra, LX

122, julio-diciembre 2008, 635-658, ISSN: 0018-215-X 
contracta sunt, turpesque abruptae amicitiae, omniaque scandala publica radicitus evulsa» ${ }^{53}$.

Especial atención merece el despliegue simbólico que pone en marcha la misión. Además de los crucifijos parroquiales y los estandartes de la Virgen que acompañaban las procesiones, al concluir la misión era práctica común plantar una cruz grande en las afueras, a la entrada del poblado, en un cruce de caminos, en el cementerio o en la plaza ${ }^{54}$. El objeto era que se conservara en el recuerdo de los feligreses el compromiso que habían asumido de «enderezar sus vidas» abandonando las «malas costumbres», los sacramentos que habían recibido y las predicaciones que habían escuchado. La cruz se establece además como un símbolo de la victoria sobre la impiedad, capaz de exorcizar al monstruo de la irreligión. La idea parece haberse concebido por primera vez en San Isidro, donde se pensó en erigir un signo visible y permanente de la victoria de la religión sobre los impíos que de ella se burlaban. Tras consultarlo con el juez de paz, que encontró la idea brillante y la comunicó a los fieles, sancionando de tal modo la decisión con el peso de la autoridad civil, los religiosos «crucem ingentis formae composuerunt, cui collocandae solemni pompa dies octava Octobris designata est ${ }^{55}$.

El carácter político-religioso de los contenidos de las predicaciones, confiadas por regla general al Padre Majesté, dice mucho acerca de cómo las autoridades concibieron las misiones. Según el informe que el juez de paz de San Isidro elevó a Rosas, Majesté se despidió de la feligresía con «...un elocuente discurso [...] para demostrar a tan numeroso auditorio los bienes que resultan a esta Provincia del paternal Gobierno de V.E. y las ventajas que ha ocasionado a nuestra Santa Religión, la Nacional, y justa causa de la Federación»56. Por su parte, el juez de paz de San Fernando dio cuenta de que el religioso había iniciado la misión con un «elocuente Sermón moral» en el que desarrolló «los clásicos argumentos del paternal Gobierno de V.E., y su piedad religiosa» y señalado la «moralidad santa como el único medio de sostener esta Causa Santa y justa...»57. Al finalizar la misión en el mismo pueblo, durante la inauguración del nuevo cementerio, el predicador federal recordó:

«los palpables beneficios obtenidos por todos los habitantes de la Provincia, del actual paternal Gobierno de V.E., de sus trabajos é incesantes desvelos por el bien general, propagación de nuestra Santa religión, y sostén de la justa causa Nacional de la Federación, que con tanta dignidad han proclamado los pueblos de la República Argentina...»58.

\footnotetext{
${ }^{53}$ De sacris expeditionibus..., f. 16.

54 A. RuBial García, La santidad controvertida..., cit., p. 277.

55 De sacris expeditionibus..., f. 7.

${ }^{56}$ El juez de paz a Rosas, 14 de octubre de 1837, en Gaceta Mercantil, 16 de octubre de 1837.

${ }^{57}$ El juez de paz a Rosas, 2 de noviembre de 1837, en Gaceta Mercantil, 14 de noviembre de 1837.

58 Ibidem.
} 
En tal ocasión el jesuita enarboló «razones científicas e incontestables» para demostrar que la Federación y la religión católica no eran más que una misma cosa y que por lo tanto «sólo en el actual sistema federal, y bajo la influencia de un Gobierno piadoso y religioso, podían haberse obtenido bienes de inconmensurable importancia, y el triunfo completo de nuestra sagrada religión», de manera que era inconcebible «poder ser un verdadero patriota federal, separándose de los principios religiosos, y de la luminosa senda del santo evangelio».

Las misiones continuaron en el otoño de 1839, según se colige de cartas e informes fechados en Morón en los meses de abril y mayo. Una de esas cartas, cursada el 4 de abril, pidió a Rosas confesionarios para la misión que se realizaría en ese mes ${ }^{59}$.Nuevamente los frutos de la misión fueron imponderables para un inmenso número de personas, aunque no pudieron beneficiarse de ella «muchas almas devotas» y se mantuvieron alejadas «otras resistentes». La identificación estrecha entre federalismo y religión, que en breve generaría conflictos entre el superior Berdugo y los padres Cabezas y Majesté, siguió marcando el tono, como revela una nota de Tomas de Cieza fechada el 19 de mayo ${ }^{60}$.

\section{CONCLUSIONES}

Las misiones coloniales se dieron en un contexto de expansión de la presencia eclesiástica en la campiña y de fortalecimiento institucional. Las relaciones entre poder civil y religioso eran relativamente estables y el cometido era «pacificar» y llevar la religión adonde la debilidad de la presencia eclesiástica impedía que llegase. Las federales se organizaron en un contexto de deterioro institucional, porque desde principios del siglo XIX el reclutamiento del clero había venido cayendo y porque la reforma de 1822 disparó una crisis político-religiosa que dividió aguas entre «reformistas»e «intransigentes», conflicto estrechamente entrelazado al que enfrentaba a unitarios y federales, que dividió a los católicos.

Pero desde la reforma el conjunto de corporaciones que constituían la «Iglesia colonial» se había transformado en un segmento del Estado provincial, lo

59 AGN X-21-3-1 (Juzgado de Paz de Morón, 1831-1841): «Estando ocupados los infrascriptos de disponer lo necesario para la Santa Misión que debe empezar el día veinte y dos del corriente han notado la falta de confesionarios pues solo hay uno en esta Iglesia y no contando con recursos para costear otro, ocurren a VE para suplicarle que teniendo noticia de que en la Iglesia Parroquial del Pilar de la antigua Recolección hay uno en los claustros del convento que no tiene uso ninguno ni menos necesario en dicho Iglesia se digne VE destinarlo para esta con lo que recibiremos un obsequio que aumentara nuestra gratitud y la de esta feligresía hacia la persona de VE.» Firman Gabriel Fuentes y Juan Bernardo Navarrete.

60 AGN, X-21-3-1 (Juzgado de Paz de Morón, 1831-1841): Carta fechada en «Morón de la Concepción mes de América 15 de 1839».

Hispania Sacra, LX

122, julio-diciembre 2008, 635-658, ISSN: 0018-215-X 
que permitió a Rosas hacer libremente uso de esa estructura para «pacificar la campiña» y consolidar el consenso federal. Las misiones federales se propusieron repristinar el orden social y moral perdido como resultado de años de convulsiones y asegurar el completo control político de las campiñas.

Nos enfrentamos, por otro lado, al problema de la relación entre los cleros secular y regular y a los vaivenes de las relaciones de ambos con el poder civil en cada momento. Pese a que el reformismo borbónico tendió a fortalecer al clero secular, no dejó de recurrir a las órdenes religiosas para atender situaciones específicas y zonas débilmente asistidas por los párrocos. En el Río de la Plata la estructura beneficial colonial generaba una situación en la que, aunque el clero no escaseara, era difícil encontrar párrocos para los curatos de campiña menos apetecibles, situación que continuó vigente por lo menos hasta la vigilia de la revolución. En parte esta situación había sido resuelta acudiendo a religiosos de las distintas órdenes, los cuales en las últimas décadas coloniales se desempeñaron como asistentes o sustitutos de los eclesiásticos seculares en las parroquias $^{61}$.

En ese contexto también las misiones permitían ejercer una acción subsidiaria de la de los curas, sobrepasados por la atención de poblaciones dispersas en enormes distancias. En contraste, hacia la década de 1830 existía una real escasez de eclesiásticos, a la que se sumaba la desconfianza de Rosas hacia un clero secular que demasiado a menudo se había mostrado indócil y que en muchos casos se había enrolado en las filas unitarias.

Desde la revolución tanto la campiña como la vida política habían cambiado. A partir de la década de 1820 los curas intervinieron mucho más activa y abiertamente en las luchas facciosas que caracterizaron el período y libraron pelea con las mismas armas de todos. El papel de «funcionario» que les había otorgado la reforma rivadaviana, que consumaba el modelo borbónico aunque con un cariz más secular, puesto que sometía las instituciones eclesiásticas al directo control del Estado, y también la necesidad de pelear por un espacio de liderazgo comunitario hasta entonces fuera de discusión, redefinieron los términos y modalidades de sus intervenciones ${ }^{62}$. Al participar de las luchas facciosas que, a fines de esa década, agitó la campiña, el clero parroquial secular perdió en buena medida su capacidad de garantizar el orden.

\footnotetext{
${ }^{61}$ María Elena BARRAL, «Parroquias rurales, clero y población en Buenos Aires durante la primera mitad del siglo XIX», en Anuario del IEHS, 20 (2005), pp. 359-388.

62 Roberto DI Stefano, El púlpito y la plaza, Buenos Aires, Siglo veintiuno editores Argentina, 2004 y María Elena BARRAL, «Ministerio parroquial, conflictividad y politización: algunos cambios y permanencias del clero rural de Buenos Aires luego de la revolución e independencia», en Valentina AYROLO (comp.) Estudios sobre clero iberoamericano, entre la independencia y el Estado-Nación, Salta, CEPIHA-UNSA, 2006, pp. 153-178.
} 
De allí que el cometido fundamental de las misiones de la década de 1830 fuera también «pacificar», pero en el sentido de fortalecer la causa federal y reparar los desequilibrios que, en opinión de los contemporáneos, habían introducido las luchas civiles. Si las misiones coloniales buscaban reformar costumbres, revalidar o unir matrimonios y, entre otros objetivos, reconciliar las enemistades cotidianas (a través de rituales precisos como el perdón de los enemigos, una práctica de la religión barroca); las misiones de Rosas desplegaron una pedagogía política que distinguía cuidadosamente a los federales de los «impíos logistas». La ruptura del consenso religioso colonial hacía de las misiones federales intervenciones que buscaban combatir una «impiedad» que en época colonial se manifestaba de manera mucho más aislada y que era considerada «patológica». Pero la polarización política post-revolucionaria y la progresiva disolución del régimen de cristiandad convirtieron en «impiedad» una amplia gama de posturas político-religiosas que Rosas, con o sin razón, identificaba con sus enemigos. 